\title{
Research of Dynamic Identification Technology on Cotton Foreign Fibers
}

\author{
Shuangxi Liu, Wenxiu Zheng, Hengbin Li, and Jinxing Wang \\ Mechanical and Electronic Engineering College, Shandong Agricultural University, Taian \\ 271018, China \\ \{shuangxiliu168, w enxiu 9013, sdau-1hb, jinxingw\}@163. com
}

\begin{abstract}
Due to the low efficiency, large errors and other practical issues of manual sorting selection method, a new cotton foreign fiber analysis instrument was developed. After fully-smashing by the ginned cotton machine, the uninterrupted uniform cotton layer was formed, and then the image of the flow cotton layer was collected by line scanning camera. Firstly the gray-scale processing is carried on to the original cotton foreign fibers image. Moreover, some other treatment such as adaptive threshold method, filter technique and enhancement processing, are used to complete the image segmentation in order to obtain clear binary image; then hollowed inner point method and neighborhood search method are used to extract the contours in order to obtain the characteristic parameters of foreign fibers. Finally the category identification and weight statistics of foreign fibers is completed based on rough sets theory. It's proved by experiments that the detection speed of this new instrument can achieve $40 \mathrm{~m} / \mathrm{h}$ and the recognition precision of this analyzer can achieve $90 \%$.
\end{abstract}

Key words: Foreign fibers; Image processing; Contour extraction; Rough sets.

\section{Introduction}

Foreign fibers are inevitable in cotton due to the mainly rely on manual picking cotton in China. The foreign fibers in cotton is non-cotton fiber and non-nature color fiber, such as chemical fiber, hair, silk, bast, plastic film, plastic film and chromonema, which are mixing with the cotton and have serious influence on the quality of cotton and its product. Foreign fiber has serious impact on textile products even the quantity is very small. Once the fiber is mixed into cotton fiber, it will not only affect the textile spinning capacity, but also form color spots in dyed fabric which may seriously affect the appearance of the fabric and make a great damage to the cotton textile industry.

Generally two methods are used to check and remove the foreign fibers in the worldwide cotton textile industry. First one is optical inspection, which scans the cotton flow in high speed by CCD (high speed camera) in the panel and the results 
can be obtained through real-time processing the scanned information by the equipment of image processing. Second one is using capacitive sensor and microelectronics technology to measure, test, and check processed cotton layer. Germany, Switzerland and Italy are the leading countries in the field of rejecting foreign fibers, such as the SCFO foreign fiber testing and detaching equipment of Trutzschler, the Cotton Sorter of Loepfe and the Sorter foreign body detecting machine of Loptex. China's equipment manufacturers and research institutes have gradually involved in this area recent years. There come out some products after years of extensive research, such as IE, DG-200OA a foreign cotton detecting facility made by Mingzheng Company in Taiwan and BARCO cotton sort machine of Zhide Company. But both domestic and abroad facilities at present have some limitations like expensive, poor clear up and lack of clarifying and calculating weight foreign fibers, which cannot meet the need of accurate measurement of foreign fiber in the cotton fiber content quality evaluation test, and it is still a blank in this research field.

Based the basis of previous studies, the authors developed an instrument for analyzing foreign fiber in cotton. It provides an effective method for check-and-stat via identifying foreign fiber and calculating its weight.

\section{Overall Structure of the Foreign Fiber Identification System Design}

The foreign fiber analyzing apparatus mainly included image acquisition system and processing systems. The overall structure of the system is shown in Fig.1.

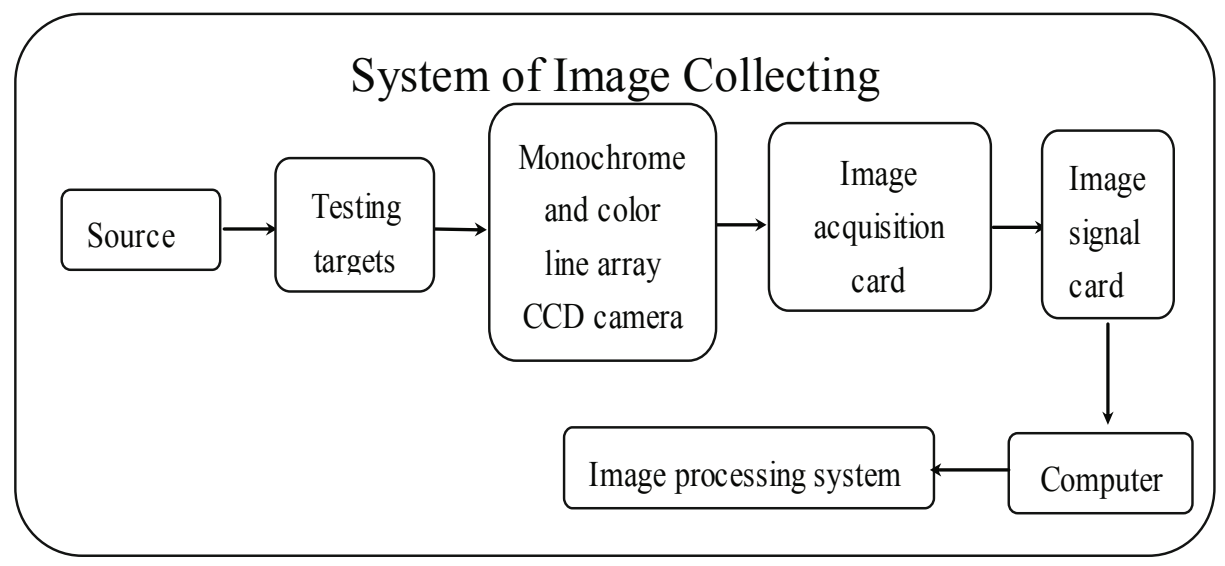

Fig. 1. System structure diagram

Firstly collect the image of foreign fiber in cotton through line scanning CCD under appropriate light source. Secondly segment and filter process the image by DSP (digital signal processing system) system to achieve image binaryzation. Then the lineament of foreign fiber is extracted. At last characteristic parameter of the foreign fiber is anglicized to carry out the classification and calculation of foreign fiber. 


\section{Image Processing of Cotton Foreign Fiber}

\subsection{Experimental Materials}

Totally 7 kinds of foreign fibers, each 10 samples were chosen for this study, black plastics cloth $(50 \mathrm{mg})$, blue silk (100mg), red silk (100mg), hemp rope $(100 \mathrm{mg})$, hair $(100 \mathrm{mg})$, red polypropylene fiber silk $(50 \mathrm{mg})$ and feather $(20 \mathrm{mg})$. Sufficient lint without foreign fiber was prepared in the time of collecting pictures. The cotton was opened sufficiently by lint opener, and continuous uniform cotton layers were formed, then different foreign fibers were mixed in the process of cotton opening. We scanned the flowed cotton layer by linen camera with the testing speed of $40 \mathrm{~m} / \mathrm{h}$. Shot 300 pieces of 24-bit bitmap images for each sample as the material for testing.

\subsection{Image Segmentation Algorithm Based on Mean-Shift}

The image segmentation is one of the key elements of image processing and machine vision, and it is a prerequisite for image analysis and pattern recognition. The purpose of image segmentation is to extract the characteristics of the target through dividing the image into meaningful connected region.

In the image processing, the 24-bit bitmap image is converted into 256 grade grayscale image. Then histogram of gray-scale image is obtained. The image of red polypropylene fiber silk, human hair and black plastic flake are chose as examples of image processing. And its original image, gray image and gray histogram are shown in Fig. 2-4.

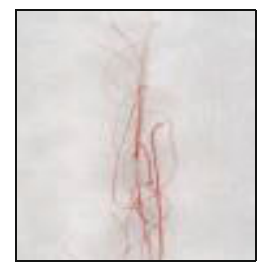

Silk

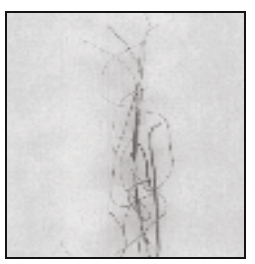

Silk

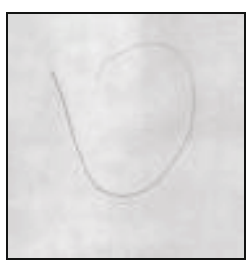

Hair

Fig. 2. Original image

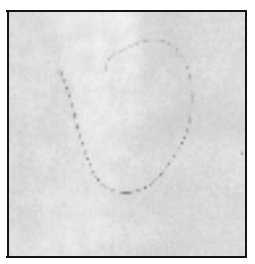

Hair

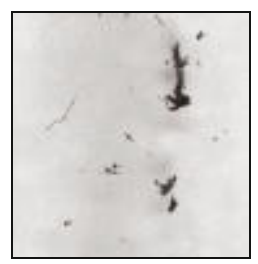

Plastic

Fig. 3. Gray image

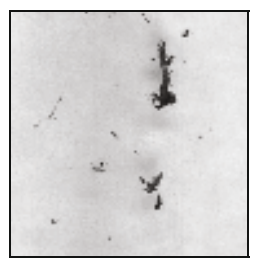

Plastic 


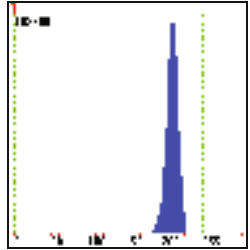

Silk

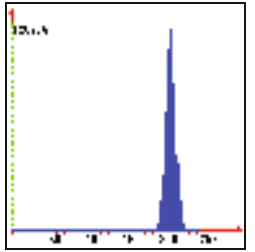

Hair

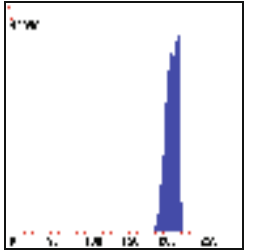

Plastic

Fig. 4. Gray histogram

The gray value of cotton layer fiber and cotton foreign fiber are mixed according to studying on the histogram. And the background of cotton layer fiber takes an absolute advantage in the whole distribution of image pixels, while the foreign fiber image only a minimal part image. The gray value range of cotton background is approximately at 230 - 255 and the gray value of foreign fiber is mostly about 230 . The image object segmentation cannot be done by using the traditional threshold segmentation technique. After taking into account of foreign fiber's gray distribution, Mean-shift adaptive threshold segmentation technology is used for image segmentation.

Based on Parzen window method of pattern recognition of estimation of probability density function, Mean-shift process is a method of kernel density estimation. Corresponding to the window function $\varphi(x)$ of Parzen window method, define kernel function $K(x)$ :

$$
K(x)=C_{k, d} k\left(\|x\|^{2}\right)
$$

$C_{k, d}$ is a normalization constant which making integral of $K(x)$ is 1 .

Take Gaussian kernel function for example:

$$
K(x)=(2 \pi)^{-d / 2} \exp \left(-\frac{1}{2}\|x\|^{2}\right)
$$

Obtain a convergence recursive formula and a Mean shift vector:

$$
y_{i+1}=\frac{\sum_{i=1}^{n} x_{i} g\left(\left\|\frac{x-x i}{h}\right\|^{2}\right)}{\sum_{i=1}^{n} g\left(\left\|\frac{x-x i}{h}\right\|^{2}\right)}
$$




$$
m_{h, G}=\frac{\sum_{i=1}^{n} x_{i} g\left(\left\|\frac{x-x i}{h}\right\|^{2}\right)}{\sum_{i=1}^{n} g\left(\left\|\frac{x-x i}{h}\right\|^{2}\right)}-x=y_{i+1}-y_{i}
$$

Image processing results by using Mean shift technology are shown in Fig.5.

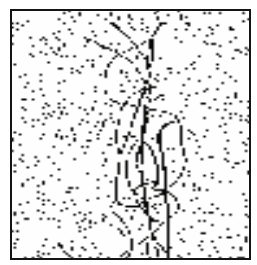

Silk

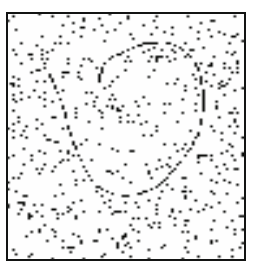

Hair

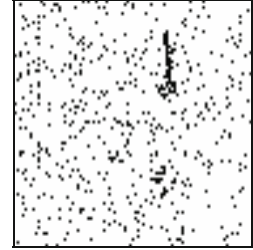

Plastic

Fig. 5. Effort image

\subsection{Contour Extraction}

It has some salt-pepper noise after image segmentationof original image. After practice test the image need twice a $7 \times 7$ median filter processing, resulted a clear binary image. The effects of binary are show in fig.6. Based on the binary image, all contour profiles are extracted by the method of tunneling internal points. Contour extraction image are showing in fig.7.

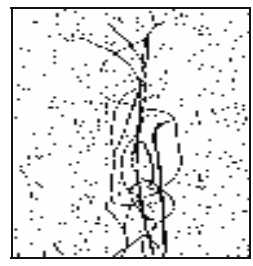

Silk

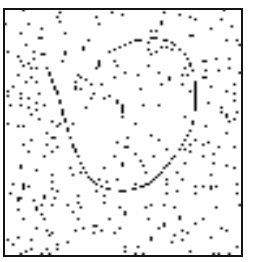

Hair

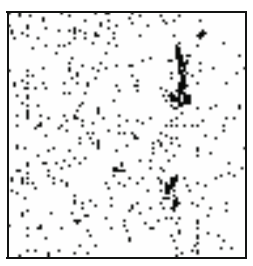

Plastic

Fig. 6. Binary image

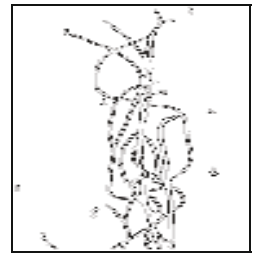

Silk

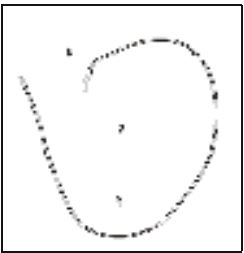

Hair

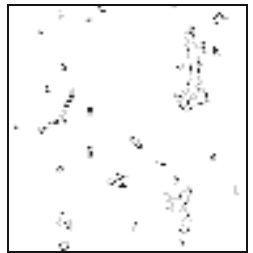

Plastic

Fig. 7. Effort image 
After all contours of foreign fibers are extracted, extract every object contour of foreign fiber by the method of 8-neighborhood search. And the object contour images are showing in fig. $8-10$.
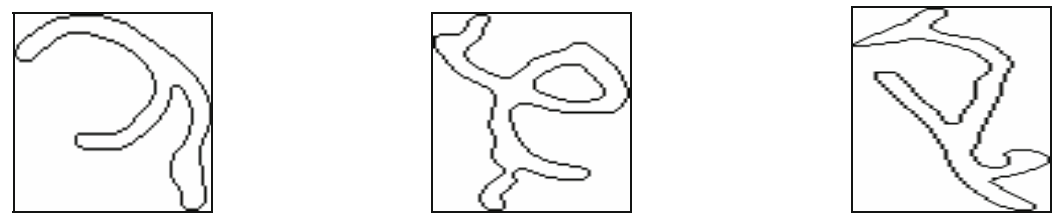

Fig. 8. Object contour image of the red polypropylene silk
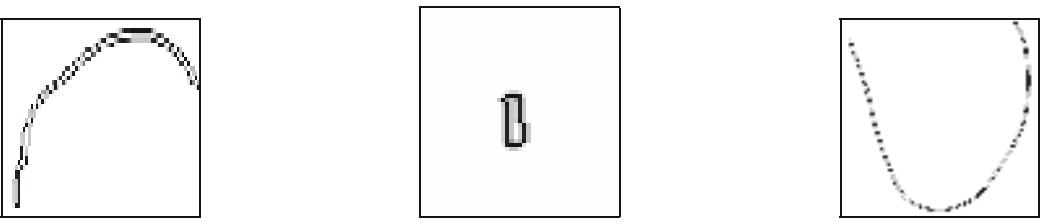

Fig. 9. Object contour image of the hair
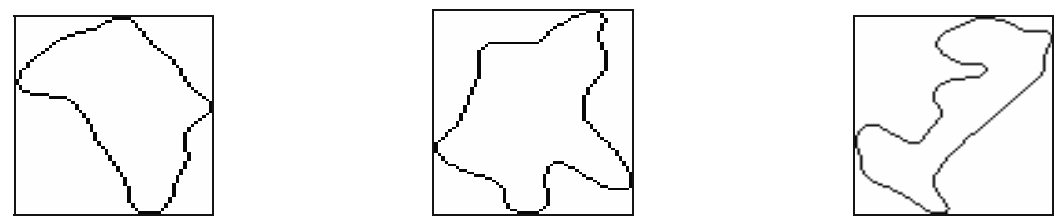

Fig. 10. Object contour image of the black plastic piece

\section{Cotton Foreign Fiber Taxonomy Based on Rough Set Theory}

The purpose of rough set theory is dividing the currently studied domain according to currently available knowledge about it and determining each domain's level of support to some concept. The basic rough set theory includes two aspects, namely knowledge express method and Rough Reduction Method.

\subsection{Knowledge Expresses Method of Rough Set Theory of Foreign Fibers}

Knowledge based on rough set theory is mainly expressed by means of information table, an effective knowledge express system. The information table summarizes the characteristics of the studied objects, which including specified object's 
characteristics and the corresponding eigen values. The table derived from the contour image of cotton foreign fiber of taking one sample of each kind of foreign material is listed as belows.

Table 1. Knowledge table of foreign fiber

\begin{tabular}{|c|c|c|c|c|c|c|c|}
\hline $\begin{array}{c}\text { Sample of } \\
\text { foreign fibers }\end{array}$ & Hair & $\begin{array}{c}\text { Hemp } \\
\text { rope }\end{array}$ & Feather & $\begin{array}{c}\text { Red } \\
\text { polypropy- } \\
\text { lene fiber } \\
\text { silk }\end{array}$ & $\begin{array}{c}\text { Blue } \\
\text { silk }\end{array}$ & $\begin{array}{c}\text { Red } \\
\text { silk }\end{array}$ & $\begin{array}{c}\text { Black } \\
\text { plastics } \\
\text { cloth }\end{array}$ \\
\hline $\begin{array}{c}\text { Contour } \\
\text { moment }\end{array}$ & 0.020 & 0.115 & 0.075 & 0.075 & 0.098 & 0.101 & 0.168 \\
\hline $\begin{array}{c}\text { Appearance } \\
\text { ratio }\end{array}$ & 2.921 & 3.987 & 5.635 & 3.489 & 5.980 & 3.370 & 4.509 \\
\hline $\begin{array}{c}\text { Duty ratio } \\
\text { Similar circle } \\
\text { degree }\end{array}$ & 0.060 & 0.189 & 0.158 & 0.456 & 0.198 & 0.175 & 0.780 \\
\hline $\begin{array}{c}\text { Red channel } \\
\text { mean }\end{array}$ & 204 & 195 & 121 & 214 & 203 & 205 & 208 \\
\hline $\begin{array}{c}\text { Green } \\
\text { channel mean }\end{array}$ & 206 & 207 & 116 & 207 & 222 & 226 & 224 \\
\hline $\begin{array}{c}\text { Blue channel } \\
\text { mean }\end{array}$ & 192 & 203 & 98 & 198 & 225 & 227 & 226 \\
\hline \begin{tabular}{c} 
Corner mean \\
\hline
\end{tabular} & 16 & 27 & 24 & 32 & 39 & 28 & 36 \\
\hline
\end{tabular}

\subsection{Rough Sets Reduction Theory of Foreign Fibers}

The Knowledge tables of foreign fibers after reduction process treatment, removing the corner property, corner detection are low-level image processing methods, as the complexity of different fiber image, the average of corner point can not be classified as an effective feature, so the corner mean column is removed. Contour moment, appearance ratio, duty cycle, similar circle degree and RGB (red, green and blue channel mean) attributes column are kept. Since contours of torque directly relevant to the area and perimeter, they are used as the first layer classification criteria and classify the foreign fibers into silk classes, strip classes and film classes. Appearance ratio reflects the rectangular outline of the target contours, duty cycle to reflect the substantial degree of the target area, and similar circle degree may reflect the roundness of the target circle, these three features are used as the second layer of classification criteria. Because mean RGB is the color information of the foreign fibers, which could not been used for classification in the global properties, but it could be used as local classification, and it can only be used as a low-attributes classify parameter. 


\section{Experimental Analyses}

\subsection{The First Layer of Classification}

With hair, polypropylene fiber, polypropylene fiber, hemp rope, colored lines, feathers, cloth, tape and plastic film 8 kinds of different fibers as a research object, total 64 contour samples were used for further analysis. The results of distribution of foreign fibers torque profile are shown in fig. 11.

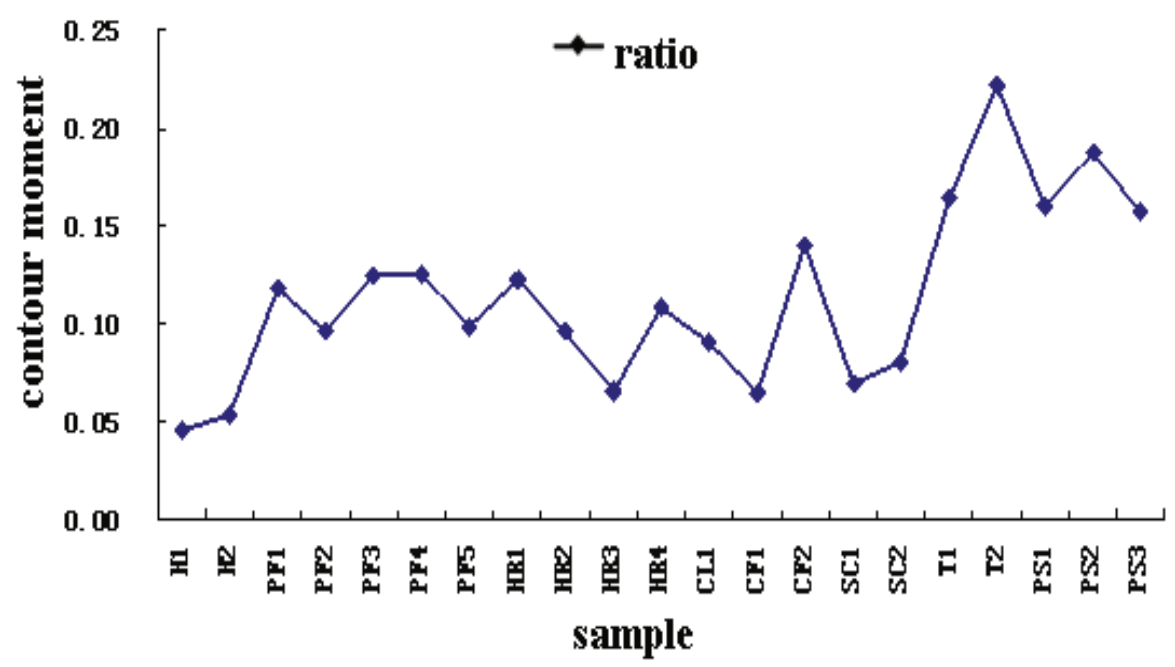

Fig. 11. The distribution map of contour moment. H: hair. PF: polypropylene fiber. HR: hemp rope. CL: colored lines. CF: chicken feathers . SC: strips of cloth. T: tape. PS: plastic sheet.

From the figure we can see that: 1) the contour moment of hair is found in between 0.04-0.06; 2) the contour moment of polypropylene fiber, hemp, colored lines, feathers, and strips of cloth are distributed between $0.06-0.15 ; 3$ ) tape and plastic film moments are located between $0.15-0.225$; and 4) There is a clear trend that the plot has three-step distribution, which is corresponded to silk class, sheet class and film class. The results are showed that by using contour moment as the first layer of classification standards, foreign fiber could be identified into silk class, sheet class or film class, and the accuracy can reach $96 \%$.

\subsection{The Second Layer of Classification}

For the stripes of blue silk, red silk, hemp rope, feathers and red polypropylene, they can be effectively identified by using features like the appearance ratio, duty cycle, roundness and RGB from the information table The foreign fiber classification 
results as shown in Figure 12, the individual who can not be identified is classified as other classes. 50 target images from each foreign fiber samples were used to do precision test, classification precision of test results as shown in table 2, and recognition rate is over $90 \%$.

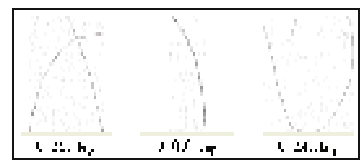

(1) Hair

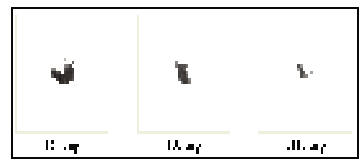

(3) Black plastic sheet

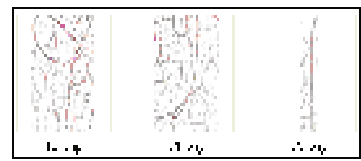

(5) Red Silk

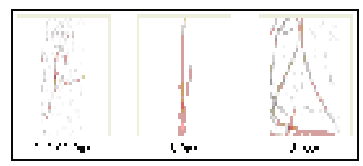

(7) Red polypropylene fiber

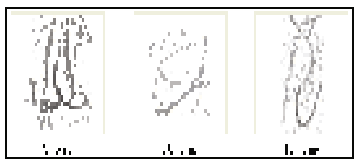

(2) Feather

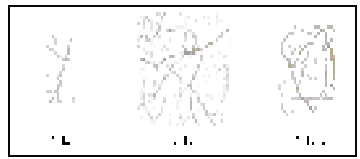

(4) Hemp rope

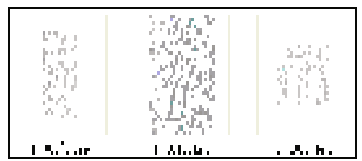

(6) Blue silk

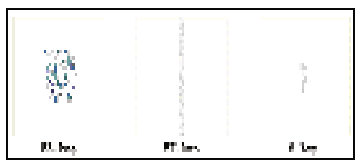

(8) Others

Fig. 12. Classification results of foreign fibers

Table 2. Accuracy test result

\begin{tabular}{|c|c|c|c|}
\hline Foreign fiber samples & The actual number & $\begin{array}{c}\text { The Identify } \\
\text { number }\end{array}$ & $\begin{array}{c}\text { Recognition rate } \\
(\%)\end{array}$ \\
\hline Hair & 50 & 50 & 100 \\
\hline Hemp rope & 50 & 48 & 95.3 \\
\hline Feather & 50 & 46 & 92.5 \\
\hline Red polypropylene & 50 & 45 & 90 \\
\hline Red Silk & 50 & 48 & 95 \\
\hline Blue silk & 50 & 47 & 94 \\
\hline Black plastic sheet & 50 & 48 & 96.3 \\
\hline
\end{tabular}

\subsection{The Building of Weight Statistical Model}

Based on the known weight and groups of foreign fibers, about 20000 images were processed, and the foreign different fiber areas were collected Then the largest 
samples and the minimum sample were removed and valid samples were selected. The average weights of each foreign fiber in unit area were calculated and results as shown in Table 3.

Table 3. Average weight per unit area

\begin{tabular}{|c|c|}
\hline Foreign fiber samples & Average weight per unit $\mathrm{area}\left(\mathrm{mg} / \mathrm{mm}^{2}\right)$ \\
\hline Hair & 4.005 \\
\hline Hemp rope & 6.006 \\
\hline Feather & 1.652 \\
\hline Red polypropylene & 2.351 \\
\hline Red Silk & 0.735 \\
\hline Blue silk & 1.175 \\
\hline Black plastic sheet & 5.166 \\
\hline
\end{tabular}

\section{Conclusions}

A cotton foreign fiber analyzer was developed in this research and seven kinds of foreign fibers were chosen as the study material and this research completes the category identification and weight statistics of foreign fibers based on rough sets theory.

Firstly the framework of foreign fiber identification system was designed and images of foreign fiber were collected. Then the algorithm of foreign fiber image was designed and then characteristic parameters of foreign fibers were extracted. By using rough sets theory, the category identification and weight statistics of foreign fibers was completed. It's proved by experiments that the detection speed of this analyzer can achieve $40 \mathrm{~m} / \mathrm{h}$ and the recognition precision of this analyzer can achieve $90 \%$.

\section{Acknowledgements}

The authors would like to thank The National Natural Science Foundation of the People's Republic of China (30971693).

\section{References}

Wang, X.L., Li, N.: The Review of cotton foreign fiber thematic. China Cotton Processing 5, 29-30 (2002)

Zhao, N., Fu, C.X.: Real-time machine vision-based detection of foreign fibers in cotton. Journal of Automation and Instrumentation 3, 24 (2008)

Tantaswadi, P., Vilainatre, J., Tamaree, N.: Machine vision for automated visual inspection of cotton quality in textile industry using color is discrimination contour. Computers and Industrial Engineering 37(12), 347-350 (1999)

Shi, G.Y.: Shallow talks the picker of cotton foreign fibers. Beijing Textile Journal 5, 51-55 (2003)

Veit, D., Hormes, I., Bergmann, J., et al.: Image processing as a tool to improve machine performance andprocess control. Journal of Clothing Sciand Tech. 8(112), 66-72 (1996) 
Wen, Z.Q., Cai, Z.X.: Convergence analysis of Mean Shift algorithm. Journal of Software 2(18), 206-211 (2007)

Zhu, Z.G., Ahi, D.J.: Digita limage processing. Publishing House of Electronics Industry, Beijing (2003)

Liu, Y.J., Ma, Y.D., Xia, C.S.: Rough sets theory and its applications in image processing.Application Research of Computers 24(4), 176-178 (2007)

Pan, L., Zhang, Z.X., Zhang, J.Q.: Application of rough sets in image feature selection. Journal of Data Acquisition and Processing 17(1), 33-36 (2002)

\section{Article Author}

Shuangxi Liu, lecturer of Shandong Agricultural University. His research interests include machine vision and pattern identification, etc.

E-mail:shuangxiliu168@163.com.

Jinxing Wang (corresponding author), received BSc and MSc both from Shandong Agricultural University in 1994 and 1997, Phd from Huazhong University of Science and Technology in 2006. Now he is an associate professor, master tutor and the mechanical engineering experimental teaching center director of Shandong Agricultural University. His research direction is precision engineering and scientific instruments. E-mail: jinxingw@163.com 